Research Article

\title{
ODeL Enabled Conceptual Model for Training Healthcare Functionaries for Managing Pandemics
}

\author{
Ruchika Kuba', Jyotsana Dikshit ${ }^{2}$ \\ ${ }^{1}$ Professor, School of Health Sciences, Indira Gandhi National Open University, New Delhi, India. \\ ${ }^{2}$ Deputy Director, National Centre for Innovation in Distance Education, Indira Gandhi National Open University, New Delhi, India. \\ DOI: https://doi.org/10.24321/2455.9199.202106
}

\section{I $\quad \mathbf{N} \quad \mathbf{F} \quad \mathbf{O}$}

\author{
Corresponding Author: \\ Ruchika Kuba, School of Health Sciences, Indira \\ Gandhi National Open University, New Delhi, \\ India. \\ E-mail Id: \\ rkuba@ignou.ac.in \\ Orcid Id: \\ https://orcid.org/0000-0002-7757-3304 \\ How to cite this article: \\ Kuba R, Dikshit J. ODeL Enabled Conceptual \\ Model for Training Healthcare Functionaries \\ For Managing Pandemics. Int J HealthCare Edu \\ \& Med Inform. 2021; 8(4): 1-12.
}

Date of Submission: 2021-07-15

Date of Acceptance: 2021-10-14

\section{$\begin{array}{llllllll}\mathbf{A} & \mathbf{B} & \mathbf{S} & \mathbf{T} & \mathbf{R} & \mathbf{A} & \mathbf{C} & \mathbf{T}\end{array}$}

Healthcare scenario is radically changing at a fast pace. This change is not only in the direction of newer investigative technologies and management strategies, but also in trying to combat the newly emerging and re-emerging diseases like Ebola, H1N1, COVID-19 and plague etc. The health care functionaries are not geared to deal with this emergent emergency situation, since their basic training lacked information about these diseases and the management and containment at such a massive scale. This paper reviews the evolving trends in providing teaching, learning, and training through ODeL with special reference to healthcare. It also reviews how ICTs are being used in sensitising and training, healthcare functionaries for management of situations like critical care, emerging disease outbreak etc. The different ODeL models have been described in this paper. The features of web of things and web of thoughts which may be an important component of the future ODeL has been highlighted. A dynamic conceptual model for training healthcare functionaries for managing pandemics has been suggested, which will enable online training in competencies using the latest technologies like personalised learning environments, the internet of things, big data, and learning analytics etc. The content and components of this model can be evolved with time and can be customised as per the requirement. The provision of connecting the trainees across geographical boundaries will enable them to remain abreast with the latest changes and strategies and apply them after improvising in their ground situations.

Keywords: Pandemic, ODeL, Capacity Development, Health Care

\section{Introduction}

With the advancement of ICTs since the mid 1990, many Open and Distance Learning (ODL) institutions have reported a shift from print-based mode to an online mode of delivery using various web technologies. ${ }^{1,2}$ The advances in instructional and cognitive science and artificial intelligence has resulted in a boost in instructional design, which is the basis of teaching-learning The advances in instructional and cognitive science and artificial intelligence has resulted in a boost in instructional design, which is the basis of teaching-learning. ODeL is a form of distance education which encompasses a convergence of phylososphy of open learning, pedagogies of distance education and learning technologies of e-learning. ${ }^{3,4}$ 
This paper reviews the evolving trends in teaching, learning, and training through ODeL with special reference to healthcare. It also highlights few examples where ICT is used in sensitising and training healthcare functionaries. The features of the web of things, and web of thoughts which are foreseen as an important component of the future ODeL have also been highlighted and a dynamic conceptual model for training healthcare functionaries for managing pandemics has been suggested.

\section{Evolving Trends in Providing Teaching, Learning, and Training Through ODel}

The conventional approach of teaching and learning is through face-to-face mode. However, when training becomes the predominant requirement, ODeL gains an edge, especially for the in-service target group. Many studies have documented ODeL as a widely accepted model of providing teaching, learning and training..$^{5-8}$ During the COVID-19 Pandemic, we witnessed a worldwide educational disruption where ODeL was the prominent methodology adopted even by institutions using the conventional mode of education and training. Administrators, teachers, and trainers identified various new ways of imparting ODeL enabled teaching, learning, and training to the end-users. ${ }^{9-12}$

The emergence of the ODeL system over the period has led to the following trends.

Open Educational Resources (OERs): OERs are shared teaching, learning, training, and research contents that could be retained, reused, revised, remixed, and redistributed under, recognised open licences. ${ }^{13}$ From the Open Course Ware (OCW) movement of Massachusetts Institute of Technology (MIT) in $2001^{14}$ followed by UNESCO using the term Open Educational Resources (OER) for the first time in the 'Forum on the Impact of Open Courseware for Higher Education in Developing Countries' in 2002, ${ }^{15}$ OER is now acknowledged globally. In a recent study conducted as a part of COL's OER for Skills Development initiative, in 28 countries, across 214 institutions nearly $64 \%$ of the faculty/ teachers of vocational institutes participated in the OER related activities. Sixty-five per cent of respondents used OER for teaching and learning purposes and $60 \%$ had used OER to supplement existing lessons. ${ }^{16}$ During the COVID era, international as well as the Country specific institutions utilised OERs for awareness, teaching and training of their workforce.

Massification of Courses: Massive Open Online Courses (MOOC): MOOCs itself was an innovation in context to the OER movement which is based on collective intelligence principles and crowdsourcing philosophy. Another innovative effort is the possibility of integrating specialised software in education in the health care sector on a large scale for example MOOCs can incorporate virtual patients. ${ }^{17}$ During the COVID-19 pandemic, health systems were strengthened through MOOCs. ${ }^{18}$

Less Desktop More Mobile: Global Digital report, 2019 reports that $66 \%$ of the world's population has a mobile phone out of which more than two-thirds of the mobile devices used today are smartphones. More than half of all mobile connections around the world are now 'broadband'. ${ }^{19}$ According to Perficient, in the year 2020, the global usage of mobile devices to access websites was $68.1 \%$, while the usage of desktops to access the websites was $28.9 \% .{ }^{20} \mathrm{WHO}$ conducted a global survey completed by 114 Member States to determine the status of mHealth in the Member States? Aspects like the adoption of initiatives, types of initiatives, the status of evaluation, and barriers to implementation were considered and categories of mHealth services like patient monitoring, managing emergencies and disasters, mobile telemedicine, etc. were surveyed. According to WHO, Mobile health will be merged with the existing eHealth domain of various countries. Building partnerships and establishing standards are required to be set for using mobile and wireless technologies to improve health and well-being. ${ }^{21}$

Game-based eLearning (GBeL): It is the use of games to enhance learning which also includes evaluation and assessment. According to Terence J. Nugent, VP marketing at Medical Marketing service, Inc, both health care professionals and the consumers can be benefitted by Gamification. Using games incentives can be incorporated like adding cigarettes, getting patient stickers and quitting smoking to encourage people to develop an ability to lead a healthy lifestyle. ${ }^{22}$ Gamification can also be used by health care professionals to learn how to manage patients and peers to win. ${ }^{23} \mathrm{~A}$ comparative study in undergraduate medical teaching found that game based elearning resulted in a higher cognitive outcome in students who received the GBeL training as compared to their peers who learned the same material. that students who received the GBeL training had a significantly higher cognitive learning outcome when compared with the students who learned the same material through conventional face-to-face mode. GBeL offered the students more fun, they liked to learn more in this style and felt more secure regarding their knowledge of the topic. Thus researchers state that GBeL is seriously considered as an alternative instructional material where student motivation may be a problem. ${ }^{24}$ Gamification can help create real like situations and ready the health care workforce to be readied in such situations by developing competencies that require real challenges to be encountered When the COVID -19 was spreading researchers invited citizen scientists to play 'Foldit' a free online game to help them in creating an effective antiviral therapy for COVID-19. ${ }^{25}$

Artificial Intelligence: Medical screening, contact tracing, 
forecasting, prediction, drug/ vaccine development, medication and treatment for the COVID-19 pandemic has been significantly been improved and the human interaction reduced due to the ongoning development in Artificial Intelligence and Machine Learning. ${ }^{26}$ Trainees can get additional support in the form of virtual tutors.

Augmented Reality: Augmented and Virtual Reality medical applications provide various apps through which medical students can virtually visualise hidden structures like the bones in the body. Augmented reality can also be used in medical training like surgeries etc. before practising on real patients. ${ }^{27}$ While dealing with pandemics advanced medical management like treatment with ventilators can be effectively delivered. Virtual-reality simulators are used for developing skills related to examination, surgery, and resuscitation in medical sciences. ${ }^{28}$

Advanced Robotics: Situations that will require the health care workers to protect themselves from potential chances of contacting infection, may require certain procedures to be conducted via robotics depending upon the mode of transmission of the disease. For example, in case of a respiratory disease dental and ENT examinations and procedures can be conducted using advanced robotics for which training can be organised or incorporated in the model. During pandemics, robotics can replace the teachers in clinical rounds and case discussions with students can be conducted virtually.

Quantum Computing: Quantum driven algorithms can be used for making informed decisions on student learning and deficits. It is expected to revolutionize triage and diagnosis. ${ }^{29}$ Large quantum of data generated by different sources, in different locations which may be geographically apart, can be shared, sorted and organized into meaningful information for epidemiological purposes for disease surveillance and management.

Big Data and Learning Analytics: Big data is all set to revolutionize the way learners learn and teachers teach. The data is analysed to gather insights that will provide clues to existing problems and enable better strategic decisions Wikipedia has also defined learning analytics. According to them learning analytics can be used for understanding improving the learning and the systems by gathering, measuring, examining and recording information related to end users and the systems through which they learn. ${ }^{30}$ The 2016 Horizon Report has also defined learning analytics as "an educational application which involves web analytics for obtaining and analysing student interactions in their online learning activities and preparing learner profiles ${ }^{31}$ During the Ebola Outbreak 2016, US Centers for Disease Control and Prevention (CDC) was able to develop a large mobile surveillance network with the help of basic text messaging data functionality. With a very low cost involved hundreds of health reporters from the local community could daily submit data using the text message through their cell phones. ${ }^{32}$ To understand the characteristics and behaviour of COVID-19 collecting and analysing the huge data sets using big data tools and techniques was resorted to. Moreover, big data analysis played a crucial role in controlling the spread of the virus. ${ }^{33}$

Personalised Learning Environment (PLE): It uses tools and technologies which enable learners to get involved at every stage of their learning and are empowered to set their own learning goals and targets. Based on the specific learning goals personalised learning environments can be created and personalised training packages can be created. Personalised learning environments enable curriculum development, increased learner engagement, greater learner retention, improved test scores, and better attendance. Such a model can be an evolving and selfupdating. The model can be updated using crowdsourcing methodology.

Internet of Things (Wearable Technology): Internet of Things (IOT) has been interpreted by Wikipedia as interactions of smart devices including physical structures like smart homes, vehicles, mobiles etc which with the help of network, appropriate softwares and sensors enable two way communication for gathering and exchanging data. ${ }^{34}$ Wearable tech is one of the most promising trends on the internet of things (IOT). Wearable, Virtual Reality Suit (like Tesla suit) is an example where one can see and feel the simulated environment instead of viewing it on screen and imagining. Immersive task simulations, in-depth product knowledge training, instant access to manuals and tutorials, efficient use of organizational resources, real-time support resources, providing immediate, inconspicuous feedback and seamless collaboration in the workplace are some of the benefits of wearable technology for ODeL..$^{35}$ Wearables, like a fitness device can be worn by people to track their vital signs like heart rate and their weight. Medical devices like glucose monitors and blood pressure monitors can send the data into the cloud. ${ }^{36}$ Similarly, in pandemics, researchers have suggested that the Pandemic spread can be reduced to a significant level by using loT-enabled/ linked devices/ applications for early and quick diagnosis, surveillance and monitoring and practicing well defined recovery protocols. ${ }^{37}$

Cloud-based Computing: It is an affordable and adaptable technology. Its characteristics of dynamic scalability, and providing virtual resources as services, has enabled organizations to manage their IT systems and services effectively.

Fog Computing: Fog computing is an alternative to cloud computing. Fog Computing became popular due to the phenomenal growth of the Internet of Things. 
Web of Thoughts: It can be defined as an emotional interaction between humans and machines which is based on neurotechnology. ${ }^{38}$ Web of thoughts in the training of health professionals and health workers will work with technologies like agents, artificial brain and collective intelligence. Communications will witness human/ technology convergence, direct brain link, digital aura etc. Edutainment will be done through active contact lenses, audio/video implants, five sense immersion and brain wave control.

\section{Use of ICT in Healthcare Training}

ICT use in healthcare sector training range from sensitizing the health functionaries to providing the latest information, practices, skills, and management protocols. An area where the ICT's could be most useful is the latest developments in the healthcare field. Outbreaks of new diseases, Pandemics or emerging diseases is one area that is being explored to sensitise the health functionaries regarding the case management of these diseases. Few examples in the health sector is discussed below.

CMC Vellore hospitals use OER to bridge the gap between education and health care in areas of need using information technology. ${ }^{39}$

Open WHO is an interactive e-platform, launched by World Health Organisation (WHO). Through the platform, WHO offers online courses for preparing the workforce during epidemics or health emergencies. The platform can host unlimited users during any emergency in the health sector and can be accessed through a computer, and mobile devices. The users can download materials, use peerdiscussion boards, and access life briefings for ongoing health emergencies. ${ }^{40}$ As of now, it is hosting about 25 courses in context to COVID-19. ${ }^{41}$

Coursera one of the world's biggest MOOCs platforms in collaboration with various universities is offering MOOCs on various streams related to epidemics, and COVID-19 pandemic like COVID-19, a clinical update, University of Florida. ${ }^{42}$ Epidemics - the Dynamics of Infectious Diseases, Penn State, ${ }^{43}$ Johns Hopkins University, is offering about five courses through Coursera.

London School of Hygiene and Tropical Medicine is offering MOOC on "COVID-19: Tackling the Novel Coronavirus." Through this MOOC, healthcare workers can get updated. They can also enrich their knowledge by learning the latest information about COVID-19, given by international experts. $^{44}$

WHO-CC at AlIMS has developed an eLearning Continuous Professionals Development (CPD) package for disseminating Evidence-Based Practices on Newborn Health for healthcare professionals. They are provided with customised modules, standard operating protocols, webinars, small videos and equipment updates. The enrolled students from different geographical areas and different clinical settings can share knowledge and clinical practices and have access to teaching by a leading Neonatologist. A certificate is also provided. ${ }^{45}$

MSF Canada developed an online briefing tool during the Ebola outbreak to train health workers to be able to respond appropriately to the Ebola outbreak. ${ }^{46}$

The CDC Learning Connection provides quality training opportunities that align with the current public health events and educational tools like e-learning design tools to the healthcare personnel. It engages public health and healthcare professionals around the world via social media messaging and a monthly e-newsletter. ${ }^{47}$

Axon Park has created a virtual reality training module for PPE training. This module unleashes the power of simulations and virtual reality technology to provide practical skills in PPE. ${ }^{48}$

\section{Models of Distance Education - A Conceptual Framework}

Prof. James Taylor has identified five generations of development of distance education to impart education at a distance. ${ }^{49}$ The technology related models are identified are as follows (Table 1).

Training specifically in health care requires certain core competencies to be achieved for which hands-on training becomes essential. In such situations, a blended mode of ODeL would be the ideal mode to be adopted.

Table I.James Taylor Models of Distance Education A Conceptual Framework

\begin{tabular}{|c|}
\hline $\begin{array}{c}\text { Models of Distance Education and Associated } \\
\text { Delivery Technologies }\end{array}$ \\
\hline The Multi-Media Model \\
Print \\
\hline Audiotape \\
Videotape \\
\hline Computer-based learning (e.g. CML/CAL/IMM) \\
\hline Interactive video (disk and tape) \\
\hline The Tele learning Model \\
\hline Audio teleconferencing \\
\hline Videoconferencing \\
\hline Audio graphic Communication \\
\hline Broadcast TV/Radio and \\
\hline Audio teleconferencing \\
\hline The Flexible Learning Model \\
\hline Interactive multimedia (IMM) \\
\hline Online Internet-based access to WWW resources \\
\hline
\end{tabular}




\begin{tabular}{|c|}
\hline Computer mediated communication \\
\hline The Intelligent Flexible Learning Model \\
\hline Interactive multimedia (IMM) \\
\hline Online Internet-based access to WWW resources \\
\hline $\begin{array}{c}\text { Computer mediated communication using automated } \\
\text { response systems }\end{array}$ \\
\hline Campus portal access to institutional processes and \\
resources \\
\hline $\begin{array}{c}\text { Source: http://www.c3l.uni-oldenburg.de/cde/media/readings/ } \\
\text { taylor01.pdf } \\
\text { Components of the ODel Enabled Conceptual } \\
\text { Model for Training Healthcare Functionaries } \\
\text { for Managing Outbreak of Emerging Diseases }\end{array}$
\end{tabular}

Being a dynamic model, its variants depend upon various parameters like availability of technology at the user as well as the organisational end, availability of resources, motivation of the trainee, research and new insights into the pandemic etc. Thus, this section of the paper will focus on the various components of the model (adopted from eLearning Framework ${ }^{50}$ and based on the WHE Learning Strategy of WHO).

\section{Organizational}

Successful implementation of a training programme requires institutional commitment. The institution should have in place comprehensive policies and implementation strategies for providing a quality assured, cost-effective, and sustainable e-training through ODeL. Human and material resources need to be allocated. External (national or international) or internal funding for development, delivery and monitoring of the training package needs to be worked out. The readiness of the organization regarding the availability of trained manpower, technical and subject matter expertise, technology, and content should be analysed. With big data and analytics in place organizations can establish systems to effectively make data-driven decisions.

In the case of pandemics, the organisation needs to collect epidemiological data like its geographical location and spread, the profile of the affected population and the micro-biological nature of the diseases etc. Authentic data related to the outbreak can be obtained from organizations like CDC, WHO etc. through collaborations.

These training packages should be target-specific. The organisation should be open to the adoption and implementation of innovations.

\section{Pedagogical}

The pedagogical aspects of ODeL include both the teaching and learning components. The objectives of the training programme followed by curriculum design should be spelt out. The pedagogic treatment of the basic content needs to be carried out, to make the content learner-friendly, engaging, interesting, comprehendible, comprehensive, flexible, and adaptable. The training package should be aimed to develop cognitive, affective, and psychomotor skills. The proposed knowledge and skills, instructional strategies, and learning technologies in relation to three domains- cognitive, affective, and psychomotor are presented in (Table 2).

Table 2.Proposed Pedagogical Design for the Training of Healthcare Functionaries for Managing Pandemics

\begin{tabular}{|c|c|c|c|}
\hline Domain & Knowledge and Skills Required & Instructional Strategies & Learning Technologies \\
\hline Cognitive & $\begin{array}{l}\text { Knowledge about epidemiology of disease, } \\
\text { investigation, and management regimes. } \\
\text { information regarding evolution across } \\
\text { different countries analysing and evaluating } \\
\text { the local situation where the outbreak has } \\
\text { occurred and creating locally appropriate } \\
\text { deviations in the management strategies based } \\
\text { on the local customs, available resources and } \\
\text { community acceptability etc. }\end{array}$ & $\begin{array}{l}\text { Tutorial, discussions, } \\
\text { interactions, } \\
\text { presentations, } \\
\text { storytelling, case studies, } \\
\text { scenario-based learning, } \\
\text { drill and practice etc. }\end{array}$ & $\begin{array}{l}\text { Synchronous and } \\
\text { asynchronous } \\
\text { discussions, webinar, } \\
\text { virtual classrooms, } \\
\text { Game based learning, } \\
\text { interactive multimedia, } \\
\text { 3-D virtual worlds }\end{array}$ \\
\hline Affective & $\begin{array}{c}\text { Motivation to imbibe new knowledge and } \\
\text { skills, } \\
\text { compassion towards the patient } \\
\text { ability to negotiate, } \\
\text { creating positive re-enforcement, } \\
\text { sharing appropriate knowledge with the } \\
\text { affected person/community with empathy etc. }\end{array}$ & $\begin{array}{l}\text { Demonstration, role } \\
\text { play, drill and practice, } \\
\text { gamification, scenario- } \\
\text { based learning, } \\
\text { storytelling etc. }\end{array}$ & $\begin{array}{l}\text { Interactive video, } \\
\text { interactive multimedia, } \\
\text { web of thoughts }\end{array}$ \\
\hline
\end{tabular}




\begin{tabular}{|c|c|c|c|}
\hline Psychomotor & $\begin{array}{c}\text { Case diagnosis and management, } \\
\text { Referral } \\
\text { soft skills (like counselling and health } \\
\text { education), } \\
\text { reporting, survey, } \\
\text { computer literacy, communication literacy, } \\
\text { diagnosis and management related } \\
\text { technological know-how etc. }\end{array}$ & $\begin{array}{l}\text { Demonstration, role } \\
\text { play, field trips, survey, } \\
\text { problem-based learning, } \\
\text { collaborations etc. }\end{array}$ & $\begin{array}{l}\text { Interactive video } \\
\text { simulation, game- } \\
\text { based eLearning, } \\
\text { augmented reality, } \\
\text { synchronous } \\
\text { discussions, providing } \\
\text { links to OER, other } \\
\text { existing digital } \\
\text { repositories etc. }\end{array}$ \\
\hline
\end{tabular}

\section{Technological}

Researchers have described the infrastructures for learning with technology for several years. ${ }^{51,52}$ Organization looking towards successfully implementing training programme through ODeL needs robust technology infrastructure in place. The evolution of cloud computing has enabled organizations to manage their IT systems and services effectively. On the other hand, Industry 4.0 has brought advancements in Information and Communication Technologies, like the internet of things, artificial intelligence, and new learning theories. These theories have provided a plethora of training opportunities in creating effective, learner-centred, interactive, engaging, quality-assured, accessible, teaching and learning opportunities. With the above technologies in hand, ODeL enabled training should be so developed that it facilitates all types of end-users.

The organisation should carefully analyse and plan the IT requirements in terms of hardware, software, connectivity etc. required both at the end of the user and at the organisational end. Requirements of IT Infrastructure to host the training are to be analysed, numbers of anticipated trainees need to be identified, and performance criteria need to be set, the required hardware and connectivity at the trainee end also needs to be identified. The mode of access used by the trainee (online or offline) should be planned. The kind of virtual learning environment is to be decided in the case of online learning. Most of the training delivered through ODeL involve both synchronous and asynchronous modes of communication. Synchronous communication occurs in real-time through web-conferencing, webinars, chat, messaging etc. In Asynchronous communication, participants choose to participate at their convenient time rather than in real-time. The medium of distribution of training could be through CD-ROM/DVD, mobile etc.

\section{Evaluation}

Assessment of the Learner: Assessment certifies the achievements of a learner and can also be used to provide feedback. If designed appropriately, it can also provide positive reinforcement to learning and motivate the learner to actively participate in the learning process. A range of tools like rubric-based feedback, tests and quizzes, e-portfolios, discussion boards, chats, simulations, online games can be planned and integrated into the learning environment. Assessment through roleplay and debates using web conferencing tools can also be considered. It is important that the assessments should be in sync with the outcome objectives and the level of learning that has been planned.

Evaluation of the Content, Infrastructure and Resources: Assuring quality both academic and technical is extremely important for the successful implementation of the programme. The content after development must be edited and vetted by content experts, and regularly updated. IT infrastructure in terms of scalability, compatibility, usability, and downtime are important issues to be considered. Similarly, learning resources should be evaluated for authenticity and relevance.

\section{Managerial}

Regular updates and upkeeping of the learning environment are very crucial in the sustenance of a training programme. Some of the other important issues of the management component of the conceptual model are to monitor quality control, economics, managing risk, security, and scheduling.

\section{Ethical}

With the advances in teaching and learning using ODeL technologies the ethical component has gained major attention and is a topic of discussion. ${ }^{53}$ The ethical component of the conceptual model include etiquette, managing the social and cultural diversities, plagiarism, privacy etc. Trainees who will be participating in the training online need to be guided on using appropriate language, for participating in group discussions and chats. Plagiarism and copyrights violations are considered unethical. The trainers and trainees should be acquainted with the use of citations and quotations in the correct manner. Privacy of data related to the trainee should be maintained. If the training is using the crowdsourcing methodology then the system should have built-in procedures to check for plagiarism and no content from the trainee end should be automatically uploaded without permission.

\section{Phases of Development of the ODel Enabled Conceptual Model}

Training in healthcare is being conducted worldwide using 
various technologies and platforms. WHO has developed a WHE training Strategy for health emergencies programmes. ${ }^{54}$ However, no literature on any standard model on which the training for health emergencies can be planned and developed was found. These phases are generally sequential and are described below.

\section{Prepare}

This can be taken up in two steps.

Identifying Problems and Devising Strategies: Identify whether the problem requires a training package, develop strategies and disseminate them. Technologies for example mobile applications can be used to get quick feedback as per the need regarding defining the target group, kind of information and skill, technologies preferred for training, strategies for implementing etc. Web analytics can also be used for making decisions related to designing strategies for developing the package (Figure 1).

Evaluating Cost-Effectiveness and Readiness: The expenditure incurred in the development and implementation of the plan should be cost-efficient and cost-effective in terms of disease diagnosis, management and further spread. The readiness of the institution in terms of the policies and approvals, availability of material, technical, manpower resources, should be ascertained. The users should be motivated and have the requisite knowledge and technology to be able to undertake the training programme ( Figure 1).

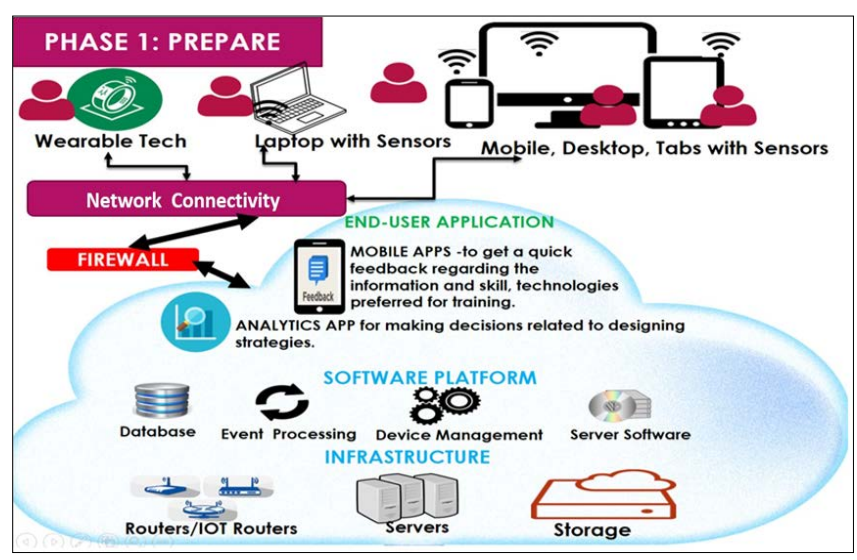

Figure I.Use of Technology in the Preparation Phase Analyse

An analysis of factors is required to be done.

Develope Trainee Profile: With respect to educational qualification, experience, work profile etc. This can be easily performed through GIS-enabled applications and mobile apps. (Figure 2).

Identify Technology Infrastructure: Available with the institution for developing and delivery of the training package and the user.
Gather Information Through External Databases: Available with international organizations like WHO and CDC. Country specific information from research organisations, epidemiological institutions etc. This information needs to be taken and regularly updated. OER can also be used for providing supplementary information and supporting the training (Figure 2). The model should have inbuilt flexibility where the learners can choose to pick up the modules for training as per their qualification and experience so that the training becomes customised for updating their knowledge and skills in the areas relevant to their job profile and can be applied to deal with the problems being faced.

Identify delivery and assessment strategies: Which will depend upon the motivation, computer literacy, net connectivity and availability of the technology. These should be aligned with the objectives of the training (Figure 2).

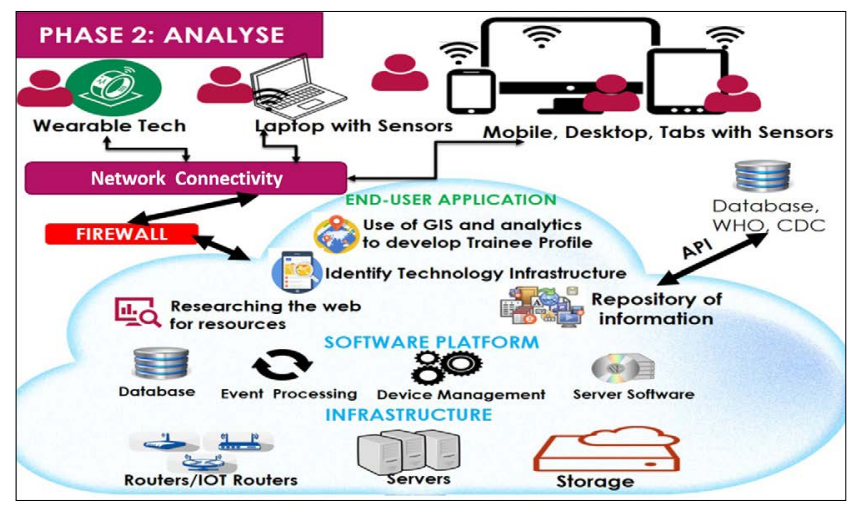

Figure 2.Use of Technology in the Analysis Phase Design

Prototyping involves deciding the format of the training programme instructional strategies and learning technologies identified in the analyse phase.

Designing and developing a prototype of the platform (Learning Management System (LMS)/Content Management System (CMS), PLE).

Content in the form of presentation, storytelling, case studies, scenario-based learning, problem-based learning, tabletop exercises, drill and practice, using audio/ video and animations, designing simulations, etc to be placed on the platform.

- Hard spots can be better explained with the help of Mobile Apps

- Gamification and problem-solving strategies can be inbuilt to assess the comprehension of the learners

- Integrating Communication and Collaborative tools into the virtual learning environment

- Building in a choice-based training system for allowing the learner to pick up the skills and the related training material relevant to his needs. For example, an epidemiologist after taking the training capsule for 
epidemiological training for the specific pandemic may feel the need to pick up health education skills as an add on or managerial skills for applying his competencies to contain the spread of the disease

- Having provision of a modular approach where the learner should be able to build his knowledge and skills in a step ladder or graded manner to achieve higher thinking order skills. For example, in the case of pandemics a learner may wish to acquire knowledge regarding the pandemic, and then in the next phase move towards patient diagnosis and management

- Deploying system and server application including the virtual environment

- $\quad$ Testing in the field under all conditions where it would be applied

- Refining based on the results and analysis of the prototype vis-a-vis the objectives for the training package

\section{Develop}

Development of Full Training Package: The prototype prepared needs to be applied for developing the full package. Webinars, teleconferences, video conferencing, and discussion forums for the package need to be integrated into the LMS. Gamification and problem-solving strategies are to be built for the entire package. The training packages designed for the different categories of health care workforce, will require different delivery packages which may have overlapping components. Skills related to the cognitive domain can be delivered through online packages. Knowledge or comprehension can be delivered through reading text material with inbuilt in-text exercises for recall and understanding. For evaluation, analysis, extrapolation or creativity, more complex assessment strategies may need to be inbuilt like scenario-based learning, problem-based questions and case studies. Similarly for psychomotor skills a mix of the online component of the training material (like simulations) needs to be packed along with hands-on skill training thus requiring a blended mode implementation model. Since we know that most of the training takes place on the job, the model can incorporate the on-job training with the learner identifying a trainer within his organisation to achieve proficiency in the desired skill. Again, the level of learning needs to be defined and could range from simple performing under supervision to selfpractice without supervision. To become proficient, we may need the learner to be able to apply his skill in different situations and customise the same as per requirement.

Since pandemics spread across continents, the training package should have the provision sharing of information and skills being developed in countries across the globe to combat the disease. This could be made possible either by regular updates in the package or the creation of a discussion forum for regular international interactions.

The training package should have both a rigorous assessment system and a monitoring mechanism inbuilt at various stages of the training. as well as to ensure effective learning as well as and feedback mechanism to enable regular updating and improvement in the training capsule.

Testing- Content after development must be tested by content experts and updated regularly as per the advances. Technical issues like Scalability (to extrapolate in a similar situation), compatibility (s/w and browser), usability, and downtime are important.

\section{Delivery of the ODel Enabled Conceptual Model}

In view of the evolving concepts and emerging technologies over time, three delivery models have been visualised and are placed below.

\section{Virtual Learning Environment based Web Support}

Based on cloud computing on top of the infrastructure and software platform layer it is proposed that the digital repository will be created from standard sources like WHO and CDC at the international level and governmental and research and teaching organisations at the national level. OER and Videos from YouTube will be used as supplementary material. Synchronous and asynchronous communications in the form of chat and discussion forums will be integrated. Learner assessment will be in the form of a quiz. To assess the projects completed by the trainee it is proposed to use an e-portfolio, and the virtual learning environment. (above Figure 3).

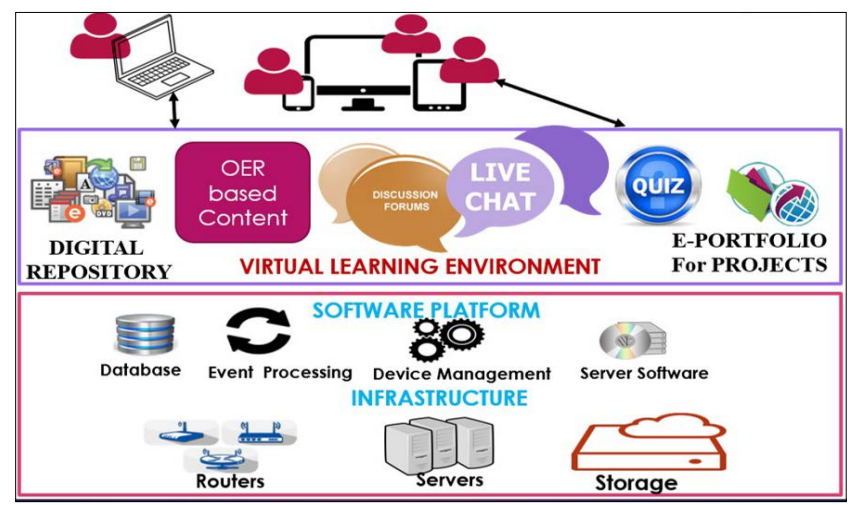

Figure 3.Virtual Learning Environment based Web Support

Learning and Content System (LCMS) and Personalised Learning Environment (PLE) based training

The LCMS and PLE based training will use the latest technologies like augmented reality, wearable tech, game-based elearning etc. to deliver the training more effectively and efficiently, to virtually connect systems and monitor practical based activities performed by the trainee. 
In case of outbreaks, specialists who well versant with the disease, can connect to the physician present in the remote area for diagnosis, management and for addressing the specific individual concerns. Tools like two-way web conferencing tools and webinars can be used for revisiting case definitions, critically analysing the use of investigations and discussions on the management protocols. In this era of crowdsourcing, this model proposes to allow the trainees to place traditionally available supportive treatment in their respective regions keeping in view the taboos, customs and traditions affecting the disease. Use of the social network to share information regarding the epidemiology of disease like age, sex and geographical distribution, characteristics symptoms, responses to treatment and sequel to the disease etc. It is also proposed to use learning analytics to identify learning paths for the trainee. The content in the form of simulation, games, demonstration, presentation, video and augmented reality is proposed to be integrated into the LCMS/PLE. A basic idea for LCMS/PLE based training is given below (Table 3).

Table 3.Components of LCMS/PLE based Training Model

\begin{tabular}{|c|}
\hline Virtually Connecting System and Wearable Tech \\
Monitoring the practical based activities \\
\hline Connecting the specialists well versant with the disease to the physician in the remote areas for \\
Case diagnosis and management \\
Addressing the specific individual concerns \\
\hline Two-way web conferencing tools and webinars for \\
\hline Revisiting case definition, \\
\hline Critically analysing the use of investigations \\
\hline Discussions on the management protocols \\
\hline Crowd sourcing methodology by involving the trainees to place \\
\hline Use of social network to share the information regarding \\
\hline Traditionally available supportive treatment taboos, customs and traditions affecting the disease \\
\hline Number of cases, their symptoms, response to treatment and sequel of the disease \\
\hline Use learning analytics \\
\hline Identify learning paths for the trainee \\
\hline Integrating content in LCMS/PLE \\
\hline Simulations, games, demonstration, presentations, video and augmented reality based content \\
\hline
\end{tabular}

Table 4.Components of Web of Things and Web of Thoughts based Training

Smart Personal Assistant can be accessed by the trainee anywhere, anytime for gathering information, clearing doubts, and problem-solving related to the problem addressed in the training package.

Web of Things/Wearable Tech: During an outbreak, the trainee can identify raised body temperature, rashes or skin eruptions by using google glass which can simulate the rash/skin eruption in the outbreak for which the

training package has been prepared. Head-mounted displays can be used for training the trainee to identify pathologies in a patient through imaging by comparing the standard and normal images of the respective body parts.

Location Based Intelligence can facilitate the gathering of data related to the outbreak of the disease in real-time, tracking of the trainees in real-time related to their field visits, and case management.

Robotics can be used to standardise the diagnostic flowcharts and treatment protocols based on analysis of the real-time data available. Online consultations can be held with specialists and researchers across borders to standardise definitions and treatment protocols.

Augmented reality: An example of Augmented Reality is the Digital Aura which is a form of visualisationof the peron's digital self and is derived from existing social and digital media. This will help the organizations to understand their target trainees better so that a flexible and customised training package can be prepared both in context to content, technology use and delivery pattern. It could be used for training on how to draw blood from the patients for investigations, teaching procedures of operating incinerators or autoclaves for managing the infectious waste being generated and mass disposal of dead bodies during the pandemics. 


\section{Web of Things and Web of Thoughts based Training}

A basic idea about on how trainings can be conducted using the elements of web of things and web of thoughts in the future is given below in (Table 4).

Managing the pandemic requires the available workforce to be geared and trained to meet the challenges posed by the current pandemic. Although different health personnel may be competent in their subject areas under normal situations, abnormal situations like the Pandemics require trained personnel in large numbers to be operational, agile and adaptable. They will also need to know how to work as a team and operate safely so as not to put themselves or others in further danger. The competencies to be developed by each category of the health personnel will depend upon their basic qualification and job responsibilities. WHO in their WHE Learning Strategy, describe the competencies to be developed through learning pathways which can be divided into technical and leadership. The technical pathway can be further divided into public health and operations. Personnel may change pathways with time and this flexibility should be an inbuilt component of the model. Each category will require a different mix of the three strategies to decide their selected learning pathway. These are formal training, relationships (mentoring, coaching and buddying) and on-the-job experience. (The 70:20:10 Model for Learning and Development ref WHO).

\section{Building Learning Pathways}

The teaching-learning domain associated with the specific competencies will require different delivery strategies. A pure online mode of delivery will be especially suitable for learning strategies aimed at the cognitive domain as the major component. Examples include creating case definitions, common presentations of the disease in the different age groups, distribution and determinants of the disease spread etc. For competencies requiring reorientation of already acquired skills, simulations embedded in the online mode of delivery is accepted e.g. operating a ventilator by a clinician. However, learning new skills to combat the disease will require hands-on training. An example could be learning; new skills of picking up clinical signs for diagnosis and management of an acute respiratory distress syndrome in the Pandemic affected individual by an ENT specialist. This is best done through on job training by selecting trained personnel locally available. This training can be supplemented with online support for reinforcement.

\section{Customising the Package for the Pandemic}

The developed model should be flexible and adaptable. It should be able to encompass the requirements of training for the specific pandemics as and when they occur and should be able to adapt itself to changes associated with the Pandemic over time.

\section{Conclusion}

Health care diagnostics and management have started using technologies like augmented reality, big data and wearable technologies. For the training of health personnel to manage Pandemics and contain the same in communities even in remote areas there is a strong need to use these technologies for developing new training packages in a very short time, customized to the specific outbreak for preparing a trained workforce who have no previous knowledge. Based on the organizational and trainee readiness, a dynamic conceptual model for training of these personnel has been proposed which has three variants viz. virtual learning environment-based web support model, LCMS/ PLE training model and web of things and web of thoughts-based training.

The various technologies suggested in the model ranges from digital repository, OER based content, e-portfolios to using augmented reality, wearable tech, learning analytics, simulations, games, location-based intelligence, digital aura technology etc. The model also proposes to develop the learning pathways for the trainees with a blended mode and flexible packages based on the need, qualification, expertise and on job requirements of the individuals. The competencies are targeted at technical, managerial and leadership arenas which could be taken up independently or in association with each other. It is expected that the dynamic conceptual model proposed by the authors in three variants will cater to the evolving need of training healthcare functionaries for managing pandemics and outbreaks of emerging diseases.

\section{Conflict of Interest: None \\ References}

1. King B, McCauslan $\mathrm{H}$, Nunan T. Converting to online course and program delivery: the University of South Australia case study. Int Rev Res Open Distrib Learning. 2001:1(2). https://doi.org/10.19173/irrodl.v1i2.21. [Google Scholar]

2. Bose K. (2003). An e-learning experience: a written analysis based on my experience in an e-learning pilot project. Int Rev Res Open Distrib Learning. 2003:4(2). https://doi.org/10.19173/irrodl.v4i2.151. [Google Scholar]

3. Arinto PB. (2016). Issues and challenges in open and distance e-learning: perspectives from the Philippines. Int Rev Res Open Distrib Learning. 2016:17(2). https:// doi.org/10.19173/irrodl.v17i2.1913. [Google Scholar] 
4. Zongozzi JN. A concept analysis of theory in South African open distance and e-learning research. Open Learning: J Open, Dist e-Learning. 2021:36(2);149163. DOI: $10.1080 / 02680513.2020 .1743172$. [Google Scholar]

5. Chatpakkarattana T, Khlaisang J. The learner support system for distance education. Creative Edu. 2012:3;4751. doi: 10.4236/ce.2012.38B011. https://m.scirp.org/ papers/26751. [Google Scholar]

6. Tait A. From place to virtual space: reconfiguring student support for distance and e-learning in the digital age. Open Praxis. 2014;6(1):5-16. [Google Scholar]

7. Kelly P, Stevens C. Narrowing the distance: using e-learner support to enhance the student experience. Eur J Open Dist E-Learning. 2010:2. [Google Scholar]

8. Wells R. The impact and efficacy of e-counselling in an open distance learning environment: a mixed method exploratory study. J Coll Stud Psychoth. 2021:1-18. DOI: 10.1080/87568225.2021.1924098. [Google Scholar]

9. Maatuk AM, Elberkawi EK, Aljawarneh S, Rashaideh $H$, Alharbi H. (2021). The COVID-19 pandemic and E-learning: challenges and opportunities from the perspective of students and instructors. J Comput higher Educ. 2021:1-18. https://doi.org/10.1007/ s12528-021-09274-2. [Google Scholar]

10. Tawafak R, ALFarsi G, Jabbar J, Malik SI, Mathew R, AlSidiri A, Shakir M, Romli A. Impact of technologies during COVID-19 pandemic for improving behavior intention to use e-learning. Int J Interact Mob Technol. 2021:15;184-198. Retrieved June 19, 2021 from https:// www.learntechlib.org/p/218695/ (Accessed on August 14, 2021). [Google Scholar]

11. Hartshorne R; Baumgartner E; Kaplan R; Mouza C, Ferdig $R E$. Preservice and in-service professional development during the COVID-19 pandemic. J Technol Teach Educ. 2020:28;137-147. [Google Scholar]

12. Crawford J, Butler K, Rudolph J, Glowatz M, Burton R, Magni P, Lam S. COVID-19: 20 countries' higher education intra-period digital pedagogy responses. J Appl Learn Teach 2020:3(1);1-21. [Google Scholar]

13. Edutopia [Internet]. Open educational resources (OER): Resource roundup [cited 2021 Aug 14]. Available from:. https://www.edutopia.org/open-educationalresources-guide (Accessed on August 14, 2021).

14. MIT [cited 2021 Aug 14]. Available from: https://odl. mit.edu/beyond-campus/opencourseware (Accessed on August 14, 2021).

15. Unesco [cited 2021 Aug 14]. Available from:. http:// unesdoc.unesco.org/images/0012/001285/128515e. pdf.

16. Phalachandra B, Abeywardena I. Open Educational Resources in the Commonwealth 2016 [cited 2021 Aug 14]. Available from: http://oasis.col.org/
bitstream/handle/11599/2441/2016_PhalachandraAbeywardena_OER-in-Commonwealth-2016. pdf? sequence $=4 \&$ isAllowed $=y$.

17. Stathakarou N, Zary N, Kononowicz AA. Beyond xMOOCs in healthcare education: study of the feasibility in integrating virtual patient systems and MOOC platforms. PeerJ. 2014:2;e672. [Pubmed] [Google Scholar]

18. Bhattacharya S, Singh A, Hossain MM. (2020). Health system strengthening through Massive Open Online Courses (MOOCs) during the COVID-19 pandemic: an analysis from the available evidence. J Educ Health Promot. 2020:9;195. https://doi.org/10.4103/jehp. jehp_377_20. [Pubmed] [Google Scholar]

19. We are Social [cited 2021 Aug 14]. Available from: https://wearesocial.com/blog/2019/04/the-state-ofdigital-in-april-2019-all-the-numbers-you-need-toknow.

20. Enge E [Internet]. Mobile vs. desktop usage in 2020. 2021 Mar 23 [cited 2021 Aug 14]. Available from: https://www.perficient.com/insights/research-hub/ mobile-vs-desktop-usage.

21. WHO [Internet]. mHealth New horizons for health through mobile technologies, Global Observatory for eHealth series Vol 3, 2011 [cited 2021 Aug 14]. Available from: https://apps.who.int/iris/handle/10665/44607.

22. The gamificaton of pharma [cited 2021 Aug 14]. Available from: https://www.pm360online.com/thegamification-of-pharma/.

23. AIJM [Internet]. Gamification: A strategic tool for organizational effectiveness [cited 2021 Aug 14]. Available from: http://www.zahiruddinarif.yolasite. com/resources/AIJM\%20June\%202012.pdf\#page=109 (Accessed on August 14, 2021).

24. Boeker M, Andel P, Vach W, Frankenschmidt A. Gamebased e-learning is more effective than a conventional instructional method: a randomized controlled trial with third-year medical students. PLoS One. $2013 \mathrm{Dec}$ 5;8(12):e82328. doi: 10.1371/journal.pone.0082328. PMID: 24349257; PMCID: PMC3857775. [Google Scholar]

25. Yasinski E [Internet]. Scientists use online game to research Covid-19 Treatment [cited 2021 Aug 14]. Available from: https://www.the-scientist.com/newsopinion/scientists-use-online-game-to-research-covid19-treatment-67230.

26. Lalmuanawma, S., Hussain, J., \& Chhakchhuak, L. (2020). Applications of machine learning and artificial intelligence for Covid-19 (SARS-CoV-2) pandemic: A review. Chaos Solitions Fractals. 2020:139(Oct);110059. https://doi.org/10.1016/j.chaos.2020.110059. [Pubmed] [Google Scholar]

27. 10 Cool augmented reality examples to know about 2019 Aug 27 [cited 2021 Aug 14]. Available from: http:// 
www.augmentedrealitytrends.com/augmented-reality/ healthcare-industry.html.

28. Singh PM, Kaur AM, Trikha A. Virtual reality in anesthesia "simulation." Anesth Essays Res. 2012;6(2):134-9. doi:10.4103/0259-1162.108289) [Pubmed] [Google Scholar]

29. Quantum Leap Into the Future of Education [cited 2021 Aug 14]. Available from: https://www.insidehighered. com/digital-learning/blogs/online-trending-now/ quantum-leap-future-education.

30. Learning analytics [cited 2021 Aug 14]. Available from: https://en.wikipedia.org/wiki/Learning_analytics.

31. NMC [Internet]. Horizon Report [cited 2021 Aug 14]. Available from: https://library.educause.edu/ /media/ files/library/2016/2/hr2016.pdf.

32. Bell BP, Damon IK, Jernigan DB, Kenyon TA, Nichol ST O'Connor JP, Tappero JW. Overview, control strategies, and lessons learned in the CDC response to the 2014-2016 Ebola epidemic. MMWR Suppl. 2016:65(Suppl-3);4-11. [Pubmed] [Google Scholar]

33. Alsunaidi SJ, Almuhaideb AM, Ibrahim NM, Shaikh FS, Alqudaihi KS, Alhaidari FA, Khan IU, Aslam N, Alshahrani MS. Applications of big data analytics to control COVID-19 pandemic. Sensors. 2021:21;2282. https://doi.org/10.3390/s21072282. [Pubmed] [Google Scholar]

34. Internet of things [cited 2021 Aug 14]. Available from: https://en.wikipedia.org/wiki/Internet_of_things.

35. eLearning Industry [Internet]. 7 Ways Wearable Technology Could Be Used In Corporate Training [cited 2021 Aug 14]. Available from: https://elearningindustry. com/7-ways-wearable-technology-used-corporatetraining.

36. Health Catalyst [Internet]. Big data in healthcare made simple [cited 2021 Aug 14]. Available from: https:// www.healthcatalyst.com/big-data-in-healthcare-madesimple.

37. Nasajpour M, Pouriyeh S, Parizi RM, Dorodchi M, Valero M, Arabnia HR. (2020). Internet of things for current COVID-19 and future pandemics: an exploratory study. J Healthc Inform Research. 2020:12(Nov);1-40. https:// doi.org/10.1007/s41666-020-00080-6. [Pubmed] [Google Scholar]

38. Flat World Business [Internet]. Web 1.0 vs Web 2.0 vs Web 3.0 vs Web 4.0 vs Web 5.0 - A bird's eye on the evolution and definition [cited 2021 Aug 14]. Available from: https://flatworldbusiness.wordpress.com/flateducation/previously/web-1-0-vs-web-2-0-vs-web-30 -a-bird-eye-on-the-definition/.

39. Using OER for healthcare education [cited 2021 Aug 14]. Available from: https://www.slideshare.net/ OCWConsortium/using-oer-for-health-care-education.

40. WHO [Internet]. OpenWHO [cited 2021 Aug 14].
Available from: https://openwho.org (Accessed on August 14, 2021).

41. WHO [Internet]. OpenWHO Course Catalogues [cited 2021 Aug 14]. Available from: https://openwho.org/ pages/catalogues\#clinical-management-channel.

42. Coursera [Internet]. Covid 19 - a clinical update [cited 2021 Aug 14]. Available from: https://www.coursera. org/learn/covid19clinicalupdate.

43. Coursera [Internet]. Epidemics - dynamics of infectious diseases [cited 2021 Aug 14]. Available from: https:// www.coursera.org/learn/epidemics.

44. Future Learn [Internet]. Covid 19: Tackling the novel coronavirus [cite2021 Aug 14. Available from: https://www.futurelearn.com/courses/covid19-novelcoronavirus.

45. Ontop [internet]. Online Neonatal Training and Orientation Programme in India [cited 2021 Aug 14]. Available from: https://www.ontop-in.org/login/index. php.

46. CDC [Internet]. Public health 101 Series [cited 2021 Aug 14]. Available from: https://www.cdc.gov/ publichealth101/e-learning/prevention-effectiveness/.

47. MSF [Internet]. [cited 2021 Aug 14]. Available from: http://www.msf.ca/en/article/msf-canada-developsonline-ebola-briefing-tool-train-health-workers.

48. Axon Park [Internet]. PPE training virtually [cited 2021 Aug 14].Available from: https://axonpark.com/ppevr-training.

49. Taylor J. Fifth generation distance education. Keynote Address presented at the 20th ICDE World Conference, Düsseldorf, Germany, April 2001. [Google Scholar]

50. Khan BH. Elearning framework dimensions and subdimensions [cited 2021 Aug 14]. Available from: http://asianvu.com/bookstoread/framework/ elearning_framework_flyer.pdf

51. Lipponen L, Lallimo J. From collaborative technology to collaborative use of technology: designing learning oriented infrastructures. Edu Med Int. 2004:41(2);1116. [Google Scholar]

52. Volungeviciene A, Tereseviciene M, Tait AW. Framework of quality assurance of TEL integration into an educational organization. Int Rev Res Open Distrib Learning. 2014:15(6). [Google Scholar]

53. Alhamad AQ, Qawasmi KI, AlHamad AQ. Building an ethical framework for e-learning management system at a university level. J Eng Economic Dev. 2014:1(1)11. [Google Scholar]

54. WHO [Internet]. WHE learning strategies [cited 2021 August 14]. Available from: https://www.who.int/ docs/default-source/documents/publications/whelearning-strategy.pdf. 